\title{
Haematoporphyrin Photosensitisation Treatment of Experimental Choroidal Melanoma
}

\author{
A. M. R. PHILlIPS*, B. H. BROWNE*, D. ALLAN†, P. J. SZCZESNY*, W. R. LEE* \\ and W. S. FOULDS* \\ Glasgow
}

\begin{abstract}
Summary
Greene amelanotic melanoma transplanted to pigmented rabbit choroid provided the experimental model for studying photosensitisation treatment of choroidal melanoma. Administration of haematoporphyrin derivative (HPD) and subsequent photoradiation with green laser light destroyed much of the melanoma with minimal side effects to normal uvea. The results of treatment were documented by fundus photography and fluorescein angiography. By 24 hours, the irradiated melanoma and surrounding retina appeared whitened and necrotic, with complete non-perfusion of the area. Over the course of one week, the clinical appearance did not alter. Histopathology at 24 hours and 8 days confirmed massive central tumour necrosis, but in all cases this was subtotal. Viable cells were evident at the periphery and also along the base of the tumour. Experimental evaluation of treatment parameters is required before this technique can be recommended for human choroidal melanoma.
\end{abstract}

Photosensitisation treatment of tumours is based on the dye, haematoporphyrin derivative (HPD), being preferentially taken up and retained by neoplastic tissue. ${ }^{1.2}$ Light of the appropriate wavelength activates intracellular HPD and causes cytotoxicity via production of singlet oxygen ${ }^{3.4}$ in a type II photochemical reaction. 5 This technique, currently termed photoradiation therapy or photodynamic therapy has been used to treat a wide variety of solid tumours. ${ }^{6.7 .8}$ Red light is employed because of its tissue penetrance, but shorter wavelengths are far more effective at activating HPD to produce singlet oxygen. ${ }^{9.10}$ It is likely that Argon green light would be preferable for treating choroidal melanomas, particularly those which are lightly pigmented. Photoradiation therapy would seem ideally suited to uveal melanoma because of their accessibility for lasering and their relatively small size. It could become a useful alternative to enucleation. The main side effect would appear to be skin photosensitivity, so that patients have to stay in subdued light for several weeks after HPD injection.

Treatment parameters require defining before an effective regimen for human use in uveal melanoma can be recommended. ${ }^{11,12}$ The combination of parameters which have to be evaluated include the interval between injection of sensitiser and laser irradiation, the most effective laser wavelength and the appropriate laser intensity.

Several experimental studies ${ }^{13.14 .15 .16}$ have been undertaken using Greene hamster melanoma growing in the anterior chamber of

From ${ }^{*}$ Tennent Institute of Ophthalmology, University of Glasgow. †Department of Clinical Physics and Bioengineering, West of Scotland Health Board, Glasgow.

Correspondence to: Dr A. Phillips, Tennent Institute of Ophthalmology, Western Infirmary, 38 Church Street, Glasgow G116NT.

Presented at the Annual Congress of the Ophthalmological Society of the United Kingdom, April 1987. 
rabbit eyes. This transmissible melanoma can also be transplanted to rabbit choroid, ${ }^{17}$ although it has not to our knowledge been used in this site to study phototherapy. This paper reports our preliminary results using this experimental model of choroidal melanoma to investigate HPD photosensitisation and the method of light delivery.

\section{Material and Method}

\section{Experimental tumour model.}

Dutch rabbits (weighing 1.5-2.5 kg) were used in all experiments. The Greene hamster melanoma was maintained by serial passage in the anterior chamber. To induce a choroidal melanoma, tissue was transplanted by a modification of the technique described by Krohn et al. ${ }^{18}$ The animals were anaesthetised using xylazine $(3 \mathrm{mg} / \mathrm{kg})$ and ketamine $(10 \mathrm{mg} / \mathrm{kg})$ intravenously, and 0.5 per cent topical tetracaine hydrochloride applied for local anaesthesia. The eye was rotated downwards and a small scleral incision made in the superotemporal quadrant, $4 \mathrm{~mm}$ behind the limbus. A modified 20 gauge lumbar puncture needle was inserted to a depth of $3 \mathrm{~mm}$ to deposit a piece of Greene melanoma in the subchoroidal space. Tumours were treated 7-14 days after transplant.

\section{Photoradiation treatment}

Rabbits were given a single intravenous injection of haematoporphyrin derivative $(5 \mathrm{mg} / \mathrm{ml})$ at $5 \mathrm{mg} / \mathrm{kg}$ body weight. For the remainder of the experiment, the animals were kept in darkness. Laser irradiation was carried out four hours after injection, under anaesthesia as described above. Argon green $(514.5 \mathrm{~nm})$ laser light was delivered to the choroidal melanoma via an operating microscope and a planoconcave contact lens. The defocussed laser beam gave a choice of $3 \mathrm{~mm}$ or $5 \mathrm{~mm}$ spot. Tumours were irradiated at a dose rate of $1 \mathrm{~W} / \mathrm{sq} \mathrm{cm}$ for 12 minutes or $2 \mathrm{~W} / \mathrm{sq} \mathrm{cm}$ for 6 minutes, giving a total energy dose of approximately $700 \mathrm{~J} / \mathrm{sq} \mathrm{cm}$.

Control experiments consisted of animals receiving HPD without subsequent irradiation or receiving laser treatment without administration of HPD.

\section{Assessment}

Melanoma growth following transplant was monitored daily by indirect ophthalmoscopy until the tumour was deemed a suitable size for treatment. The results of photodynamic therapy were assessed at 24 hours ( 8 animals) or 8 days ( 4 animals) by the following methods: fundus photography, fluorescein angiography using $0.15 \mathrm{ml}$ sodium fluorescein (10 per cent), and histopathology. After sacrifice, both eyes were enucleated and fixed in 2 per cent glutaraldehyde. Tumour and normal tissues were paraffin embedded, sectioned and stained for light microscopy.

\section{Results \\ Fundoscopy}

Pre-treatment: Within two weeks of implantation, the transplanted tumour tissue grew to form a discrete choroidal melanoma (Fig. 1). In this time, it attained a base diameter of 4-5 $\mathrm{mm}$ and height $1-1.5 \mathrm{~mm}$.

The fundus appearance of control tumours treated with HPD alone or laser at $1 \mathrm{~W} / \mathrm{sq} \mathrm{cm}$ was identical to the untreated Greene melanoma. When the power density was increased to $2 \mathrm{~W} / \mathrm{sq} \mathrm{cm}$, thermal effects of laser without HPD produced blanching of the irradiated area, visible after twenty-four hours.

Post-treatment: Figures 2a-d show the fundus appearance of a melanoma untreated and at one to seven days following photoradiation treatment. Within twenty-four hours of lasering, tumours turned white and irradiated, surrounding retina looked opaque. Over the next week, the tumour opacity decreased in size and underlying choroidal atrophy was apparent. Retinal vessels appeared haemorrhagic, but this was confined to the lasered region.

Serous retinal detachment around the tumour was a common finding, particularly if it was present to a lesser degree before therapy, although it largely resolved in those animals assessed during eight days.

Photoradiation therapy at these laser intensities has caused no obvious side effects to

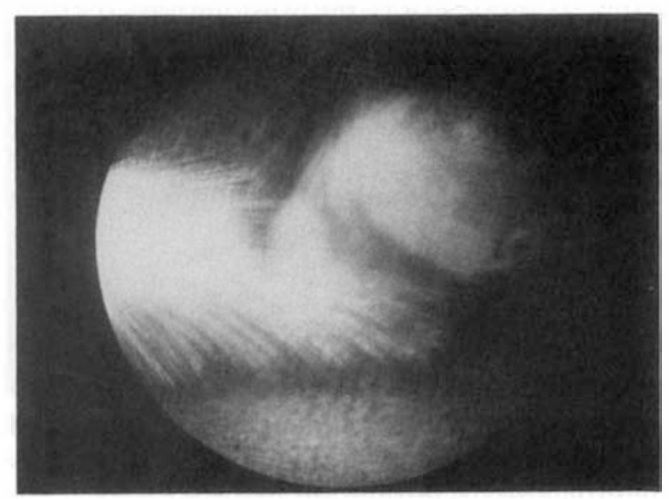

Fig. 1. Fundus appearance of Greene amelanotic melanoma in rabbit choroid. 


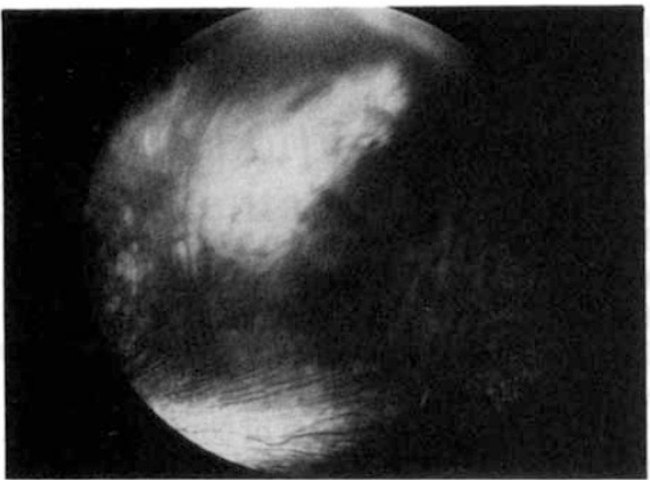

Fig. 2a. Greene melanoma, prior to treatment.

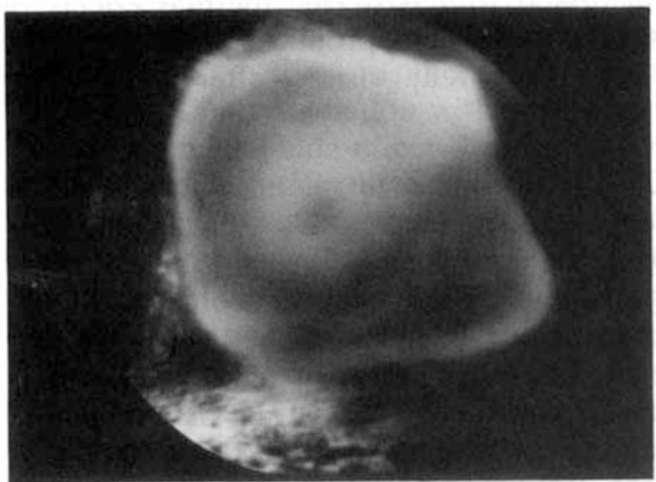

Fig. 2c. Melanoma, 4 days post-treatment.

normal tissues; cornea, lens and vitreous remained clear.

\section{Fluorescein Angiography}

An example of a fluorescein angiogram of Greene choroidal melanoma is shown before (Fig. 3) and after photoradiation therapy (Fig. 4). The typical patchy hyperfluorescence was replaced by an area of complete hypofluorescence. Irradiated retinal vessels were no longer patent, and no recovery of tumour circulation or retinal circulation was evident over the course of one week.

\section{Histopathology}

Pre-treatment: The melanoma grew from the posterior choroid, separating normal choroidal melanocytes and causing exudative retinal detachment (Fig. 5). The tumour was amelanotic and of epithelioid cell type with large nuclei, prominent nucleoli and frequent mito-

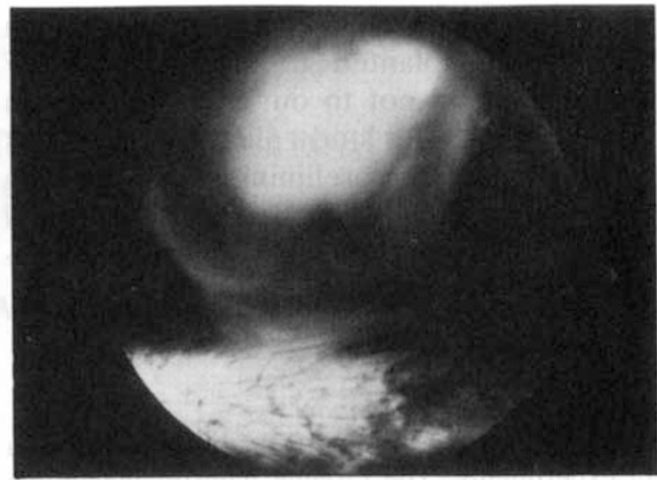

Fig. 2b. Melanoma, 24 hours after photoradiation therapy: $5 \mathrm{mg} \mathrm{HPD/kg}, 1.99 \mathrm{~W} / \mathrm{sq} \mathrm{cm} ; 716 \mathrm{~J} / \mathrm{sq} \mathrm{cm}$.

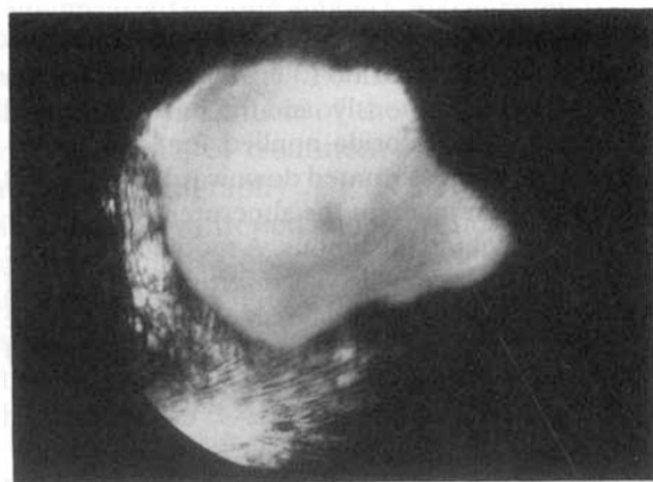

Fig. 2d. Melanoma, 7 days post-treatment.

tic figures. Blood vessels within the tumour were often widely spaced. At a relatively small size, foci of spontaneous haemorrhagic necrosis occurred.

Histopathology of control tumours confirmed no apparent laser effect when laser

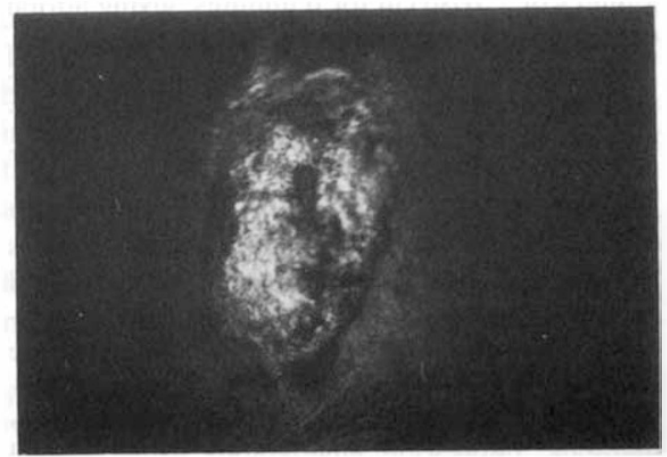

Fig. 3. Fluorescein angiogram of Greene choroidal melanoma, untreated. 


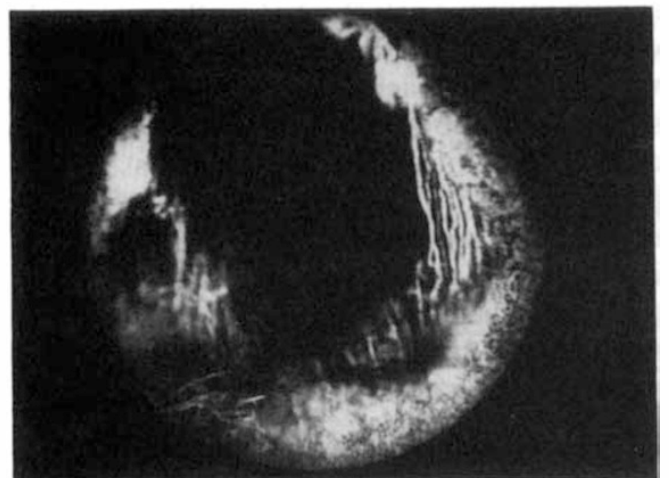

Fig. 4. Angiogram 7 days after HPD photoradiation therapy: $1.91 \mathrm{~W} / \mathrm{sq} \mathrm{cm} ; 689 \mathrm{~J} / \mathrm{sq} \mathrm{cm}$, showing complete absence of fluorescence in irradiated area.

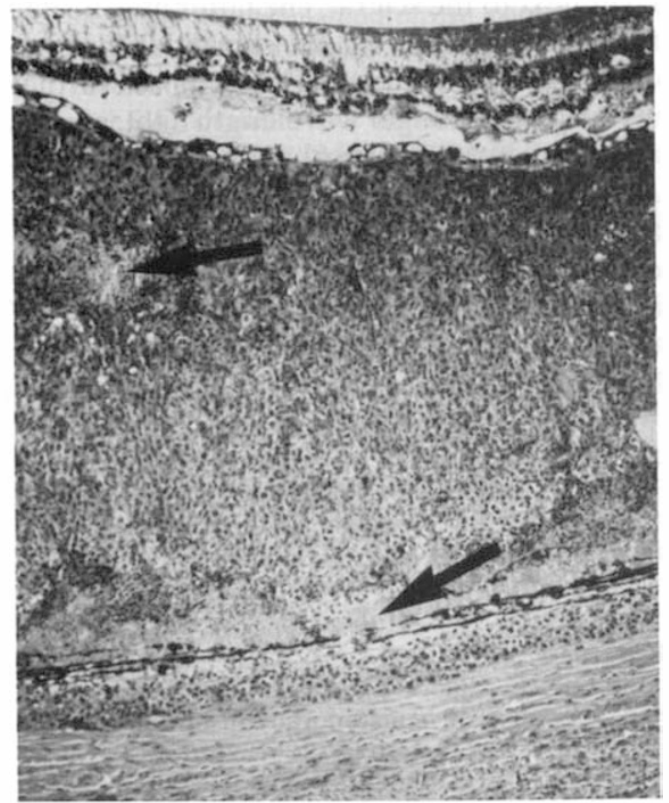

Fig. 5. Histology of untreated choroidal Greene melanoma and overlying retina. The lines of pigment are normal choroidal melanocytes. Areas of spontaneous necrosis are shown ( $\uparrow)$. Haematoxylin and eosin, $\times 90$.

light alone was delivered at $1 \mathrm{~W} / \mathrm{sq} \mathrm{cm}$. A power density of $2 \mathrm{~W} / \mathrm{sq} \mathrm{cm}$ to deliver the same laser dose caused significant necrosis of tumour and retina, attributed to hyperthermia. Animals receiving only HPD showed normal eye histology.

Post-treatment: Twenty-four hours after photoradiation therapy, histology showed extensive central necrosis of the tumour and a necrotic overlying retina. Tumour cells had pyknotic or fragmented nuclei, with pale eosinophilic cell outlines (Fig. 6a). The retina showed fragmentation, mostly in the outer and inner nuclear layers and necrosis of the underlying retinal pigment epithelium. Tumour vessels were partially or completely thrombosed with fibrin clots and in some, vessel endothelial walls had ruptured. However, apparently viable tumour cells were consistently found in the suprachoroidal space, seemingly behind spontaneously necrotic areas and lines of pigment. Viable tumour was identified in all cases at the margins (Fig. 6b). Mitotic figures were visible and at eight days after treatment, peripheral tumour was showing active signs of proliferation.

\section{Discussion}

The Greene amelanotic melanoma growing in pigmented rabbit choroid appears to be a useful, fast growing model for studying haematoporphyrin photosensitisation treatment of uveal melanoma. The obvious advan-

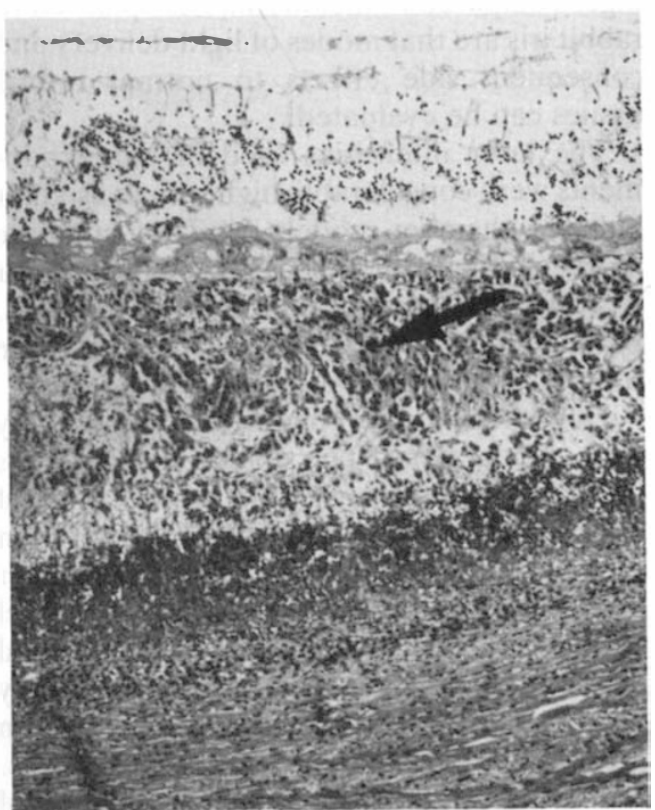

Fig. 6a. Histopathology at 24 hours after photoradiation therapy: $H P D, 1.94 \mathrm{~W} / \mathrm{sq} \mathrm{cm} ; 698 \mathrm{~J} / \mathrm{sq} \mathrm{cm}$. Irradiated retina is fragmented; tumour is necrotic with preservation of cell outlines $(\uparrow)$. Haematoxylin and eosin, $\times 100$. 


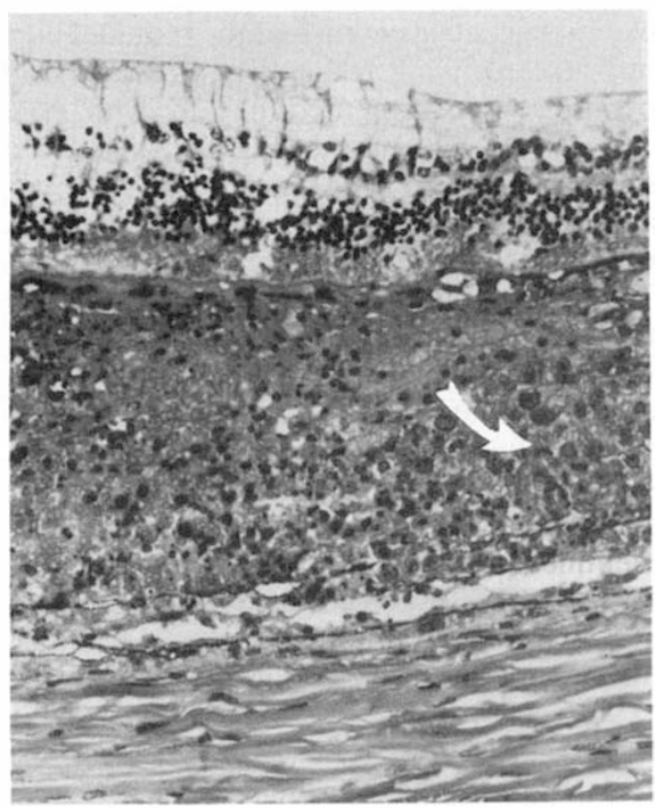

Fig. 6b. Periphery of melanoma treated with $5 \mathrm{mg}$ $\mathrm{HPD} / \mathrm{kg}, 1.99 \mathrm{~W} / \mathrm{sq} \mathrm{cm} ; 7^{1} \mathrm{~h} 6 \mathrm{~J} / \mathrm{sq} \mathrm{cm}$ after 24 hours. Viable cells ( $\uparrow$ ) can be seen at margin of necrotic tumour. Haematoxylin and eosin, $\times 250$.

tages compared to melanoma transplanted to rabbit iris are that modes of light delivery and consequent side effects to normal retinal tissues can be evaluated.

The laser intensities used in our experiments were considerably higher than used for anterior chamber models. ${ }^{15.16}$ They compare more closely with first reported values for treatment of human choroidal melanomas, which required large doses and more than one treatment session. ${ }^{11,12}$

Our early results of photoradiation therapy were encouraging. The dosage of HPD was therapeutic, although the time interval between injection and laser was shorter than used clinically. From twenty-four hours after injection, the blood haematoporphyrin level is negligible which might result in unequal distribution of HPD in cells that are newly dividing. An interval of four hours was chosen for initial experiments in order to avoid this. This also meant that well vascularised normal ocular tissues contained high concentrations of sensitiser, notably iris, retina and choroid ${ }^{18}$ making them susceptible to photodynamic action if irradiated. Increasing the interval should improve selectivity by allowing washout of HPD from non-malignant tissues. We wanted to keep haematoporphyrin levels constant in order to study the laser variables. The combination of HPD and green laser light produced central tumour necrosis, seemingly through a direct cytotoxic effect and by causing vascular thrombogenic ischaemia. No thermal effects were produced by laser irradiation at a dose rate of $1 \mathrm{~W} / \mathrm{sq} \mathrm{cm}$ whereas hyperthermia contributed when using a laser density of $2 \mathrm{~W} / \mathrm{sq} \mathrm{cm}$.

In these preliminary experiments, the edges of the tumours were clearly not receiving a full dose of irradiation, leaving viable melanoma cells at the margins and also often as a discrete layer next to the sclera. The latter may be due to a protective effect by choroidal melanocytes or hypoxic areas. This requires further investigation; longer wavelength light, such as red laser light $(630 \mathrm{~nm})$ may be necessary. Another possibility is to use transscleral in addition to transpupillary light delivery. The delivery system will also be modified to improve irradiation of the periphery of tumours. These steps are necessary before long term effects of treatment can be studied.

The authors would like to acknowledge the Cancer Research Campaign for financial support, Professor J A Oosterhuis for providing the Greene melanoma, and Professor $T$ G Truscott for supplying haematoporphyrin derivative.

\section{References}

${ }^{1}$ Lipson RL, Blades EJ, Olsen AM: The use of a derivative of hematoporphyrin in tumor detection. J Natl Cancer Inst 1961, 26: 1-11.

${ }^{2}$ Dougherty TJ, Grindey GB, Fiel R, Weishaupt KR, Boyle DG: Photoradiation therapy. II. Cure of animal tumors with hematoporphyrin and light. $J$ Natl Cancer Inst 1975, 35: 115-9.

${ }^{3}$ Weishaupt KR, Gomer CJ, Dougherty TJ: Identification of singlet oxygen as the cytotoxic agent in photoinactivation of a murine tumor. Cancer Res 1976, 36: 2326-9.

${ }^{4}$ Bodaness RS and Chan PC: Singlet oxygen as a mediator in the hematoporphyrin catalysed photooxidation of NADPH to NADP in deuterium oxide. J Biol Chem 1977, 252: 8554-60.

${ }^{5}$ Foote CS: Mechanisms of photooxygenation. In porphyrin localisation and treatment of tumors. AR Liss, 1984, 3-18.

${ }^{6}$ Dougherty TJ, Kaufman JE, Goldfarb A, Weishaupt KR, Mittleman A: Photoradiation Therapy for the treatment of malignant tumours. Cancer Res 1978, 38: 2628-35. 
${ }^{7}$ Wile AG, Coffey J, Nahabedian MY, Baghdassarian R, Mason GR, Berns MW: Laser photoradiation therapy of cancer: an update of the experience at the University of California. Lasers Surg Med 1984, 4: 5-12.

${ }^{8}$ Dougherty TJ: An overview of the status of photoradiation therapy. Prog Clin Biol Res 1984, 170: 75-87.

${ }^{9}$ Kinsey JH, Cortese DA, Moses HL, Ryan RJ, Branum EL: Photodynamic effect of hematoporphyrin derivative as a function of optical spectrum and incident energy density. Cancer Res 1981, 41: 5020-6.

${ }^{10}$ van Gemert JC, Berenbaum MC, Gijsbers GHM: Wavelength and light-dose dependence in tumour phototherapy with haematoporphyrin derivative. Br J Cancer 1985, 52: 43-9.

11 Tse DT, Dutton JJ, Weingeist TA, Hermsen VM, Kersten RC: Hematoporphyrin photoradiation therapy for intraocular and orbital malignant melanoma. Arch Ophthalmol 1984, 102: 833-8.

${ }^{12}$ Bruce RA: Evaluation of hematoporphyrin photoradiation therapy to treat choroidal melanomas. Lasers Surg Med 1984, 4: 59-64.

${ }^{13}$ Liu LHS and Ni C: Hematoporphyrin phototherapy for experimental intraocular malignant melanoma. Arch Ophthalmol 1983, 101: 901-3.

${ }^{14}$ Sery TW and Dougherty TJ: Photoradiation of rabbit ocular malignant melanoma sensitized with hematoporphyrin derivative. Curr Eye Res 1984, 3: $519-28$.

15 Gomer CJ, Doiron DR, White L, Jester JV, Dunn S, Szirth BC, Razum NJ, Murphree AL: Hematoporphyrin derivative photoradiation induced damage to normal and tumor tissue of the pigmented rabbit eye. Curr Eye Res 1984, 3: 229-37.

${ }^{16}$ Franken KAP, van Delft JL, Dubbelman TMA, de Wolff-Rouendaal D, Oosterhuis JA, Star WM, Marijnissen HPA: Hematoporphyrin derivative photoradiation treatment of experimental malignant melanoma in the anterior chamber of the rabbit. Curr Eve Res 1985, 4: 641-54.

${ }^{17}$ Krohn DL, Brandt R, Morris DA, Keston AS: Subchoroidal transplantation of experimental malignant melanoma. Am J Ophthalmol 1970, 70: 573618.

${ }^{18}$ Gomer CJ, Jester JV, Razum NJ, Szirth BC, Murphree AL: Photodynamic therapy of intraocular tumors: examination of hematoporphyrin derivative distribution and long-term damage in rabbit ocular tissue. Cancer Res 1985, 45: 371825 . 